\title{
Dr. Unnas dermatologische Preisaufgabe
}

lautet für das Jahr 1896:

„Das Vcrlialleii der E$\mu$ ithelfaseiung während der Entwickelung: der weichen Muttermäler und der alveolären Carcinome.1*

Bedingungen.

1. Die Bewerbung ist eine vollkommen unbeschränkte; jedoch ist das Thema speciell nach Inhalt und Umfang für medizinische Doktoranden $b \theta$ rechnet.

Die Aufgabe wird jährlich um Ostern ausgeschrieben.

Die Arbeit muss bis zum 1. Dezember desselben Jahres eingeliefert $\Lambda$ verden.

Der Preis beträgt für dieses Jahr Mk. ÍKK) (ncunhundert Mark).

Die Exeilung des Preises findet im Laufe dos Monats Januar des auf die Ausschreibung folgenden Jahres statt.

Die Arbeit ist, mit einem Motto versehen, an die Verlagsbuch-handlung Leopold Voss in Hamburg, Hohe Bleichen 34, kostenfrei einzusenden nebst einem versiegelten Briefe, welcher Namen und Adresse des Verfassers enthält und aussen dasselbe Motto tràgt.

262

Mitteilungen.

Die Arbeit muss in deutscher Sprache und durehaus leserlich auf ein-seitig beschriebenen Bogen geschrieben sein. Die notwendigen Zeichnungen sind auf besonderen Blättern beizulegen.

Belegpräparate sind in raöglichst reicher Auswahl, gut verpackt der Arbeit beizufiigen; die der preis $7 / 8$ ekrönten Arbeit angehörigen verbleiben im Becitze des Preisgebers.

9. Erläuterungen zur diesjährigen Aufgabe: Das Hauptgewicht wird auf eine gute Färbung des Epithelprotoplasma und der Epithelfase-rung gelegt, sodass die eigentiimlichen Veränderungen (Metaplasie) der Epithelien, welche mit ihrer Abschnürung vom Mutterboden und ihrem Fortwuchern in der Cutis einhergehen (Verlust der Faserung, Veiänderung der Tingibilität), klar hervortreten.

Ueber die Methoden der Färbung des Epithelprotoplasma s. Monatsh. f. prakt. Derm. 1894. Bd. XIX. pag. 277, der Färbung der Epithelfasern s. Monatsh. f. prakt. Derm. 1894. Bd. XIX. pag. 1. Uebrigens ist der Benutzung und Erfindung anderer guter und besserer Färbemethoden der weiteste Spielraum gegönnt,

Ueber die Metaplasie der Epithelien bei der Entstehung der weichen Naevi und der alveolären Carcinome vergl. in Unnas Handbuch der Histopathologie der Haut (Hirschwald, 1894) die Kapitel über Naevi und Carcinom. Die dort nur in grossen Umrissen gezeichneten Vorgänge sollen möglichst im Detail studiert and durch gute Präparate erläutert werden. Eine Heranziehung der Frage nacîi dem Einfluss des Figmentes auf die in Rede stehende Metaplasie ist nicht aus-geschlossen. 